\title{
Reactive Oxygen Metabolite Measurement
}

National Cancer Institute

\section{Source}

National Cancer Institute. Reactive Oxygen Metabolite Measurement. NCI Thesaurus.

Code C122146.

The determination of the amount of reactive oxygen metabolite present in a sample. 